\title{
Análise do Desempenho Acústico do Cross Laminated Timber (CLT)
}

\author{
Carlos H. C. Puga*, Stelamaris R. Bertoli
}

\section{Resumo}

As habitações têm como finalidade principal abrigar e proteger, de maneira confortável, seus usuários. Para isso, é necessário que os materiais usados durante a construção atendam às especificações recomendadas em normas de qualidade e desempenho. Os novos materiaise e tecnologias e novos materiais devem apresentar desempenho adequado quando comparando com o exigido em norma de desempenho, a NBR 15575 (2013). Nesse contexto de surgimento de novas tecnologias, pode-se mencionar o Cross Laminated Timber (CLT). Esta pesquisa teve como objetivo avaliar o desempenho acústico do CLT quanto ao isolamento sonoro aéreo quando utilizado como vedações externas verticais. Para isso foi avaliado o isolamento sonoro aéreo em campo de 3 fachadas de uma edificação e 2 fachadas em laboratório, com espessuras de 80 e 120 mm, respectivamente. Os principais resultados da pesquisa são apresentados no texto.

\section{Palavras-chave:}

Cross Laminated Timber (CLT), isolamento sonoro aéreo, vedações verticais externas.

\section{Introdução}

O sistema construtivo CLT (Cross Laminated Timber) é composto por lâminas de madeira unidas sob alta pressão por adesivos estruturais, à base de poliuretano No Brasil, a madeira utilizada para a fabricação do CLT é o pinus. O uso do CLT tem ganhado cada vez mais espaço no mercado devido às questões de recursos naturais e sustentabilidade.

Devido à diversidade de aplicação do CLT como sistema construtivo é necessário que ele atenda os requisitos de conforto e segurança para o usuário como os recomendados pela norma de desempenho NBR 15575 (2013), entre elas o desempenho acústico. Este projeto teve como objetivo avaliar desempenho acústico, quanto ao isolamento sonoro aéreo em campo e em laboratório do CLT empregado como tecnologia construtiva de vedações verticais externas.

\section{Resultados e Discussão}

Resultados obtidos em Campo: Foram avaliadas 3 fachadas em CLT de uma edificação habitacional. $O$ procedimento de medição seguiu a norma ISO 16283-3 (2016). A partir dos dados medidos, calculou-se os valores do parâmetro Diferença de Nível Padronizada (DnT) em função de frequência e apresentados na Figura 1A. Com procedimento ISO 717-1 (2013), calculou-se a diferença de diferença padronizada de nível ponderado (DnTw) para cada fachada apresentados na Tabela 1. Esse parâmetro é usado para verificar o desempenho do isolamento sonoro do material, sob a forma de um número único.

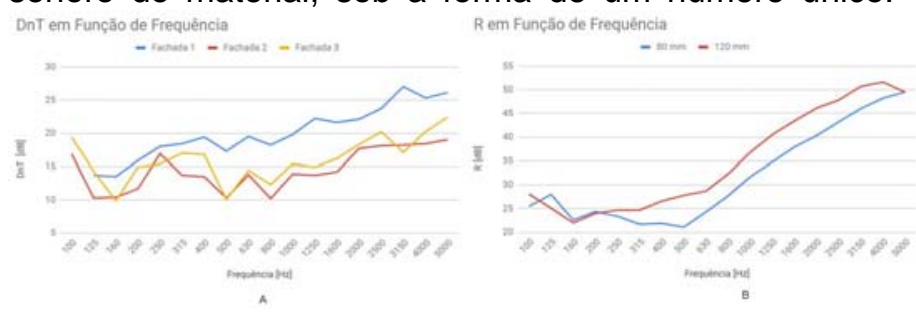

Figura 1. Isolamento acústico em campo e em laboratório.

Resultados obtidos em Laboratório: Os ensaios em laboratório foram realizados no IPT, seguindo o procedimento da norma ISO 140 onde foram avaliadas duas fachadas, com espessuras de $80 \mathrm{~mm}$ e $120 \mathrm{~mm}$, respectivamente, ambas com massa específica igual a $500 \mathrm{~kg} / \mathrm{m}^{3}$. Os resultados do índice de redução sonora (R) em função de frequência são mostrados na Figura 1B. Empregando a norma ISO 717-1 (2013), calculou-se o índice de redução sonora ponderado (Rw) das fachadas cujos valores estão na Tabela 2.

Tabela 1. DnTw para cada fachada.

\begin{tabular}{|c|c|c|c|}
\hline Fachada & 1 & 2 & 3 \\
\hline DnTw $[\mathrm{dB}]$ & 21 & 15 & 21 \\
\hline
\end{tabular}

Tabela 2. Rw para cada fachada

\begin{tabular}{|c|c|c|}
\hline Fachada & $80 \mathrm{~mm}$ & $120 \mathrm{~mm}$ \\
\hline Rw [dB] & 29 & 34 \\
\hline
\end{tabular}

\section{Conclusões}

A norma NBR 15575 (2013) recomenda para o desempenho acústico em ruídos de classe I (habitações distantes de fontes de ruído intenso) o valor mínimo de $20 \mathrm{~dB}$ e $5 \mathrm{~dB}$ a mais para as classes II e III de ruído. Desta forma conclui-se que CLT atingiu o mínimo de isolamento acústico requerido somente para as fachadas 1 e 3.

Para fachadas a norma NBR 15575-3 (2013) recomenda um valor mínimo de Rw de $25 \mathrm{~dB}$ para ruídos de classe 1 e $30 \mathrm{~dB}$ para os ruídos de classe II. Pela Tabela 2 observa-se que as fachadas de CLT com 80 $\mathrm{mm}$ de espessura atendem ao desempenho mínimo na classe I, e as de espessura de $120 \mathrm{~mm}$ atendem ao nível intermediário da classe I, mas também o mínimo da classe II.

\section{Agradecimentos}

\section{Ao CNPq.}

ASSOCIAÇÃO BRASILEIRA DE NORMAS TÉCNICAS. NBR - 15575 - 3: Edificações habitacionais - Desempenho Parte 3: Requisitos para os sistemas de pisos. Rio de Janeiro, 2013.

INTERNATIONAL ORGANIZATION FOR STANDARDIZATION. ISO 16283-3: Acoustics - Field measurement of sound insulation in buildings and of buildings elements - Part 3: Façade sound insulation. Genebra, 2016. , ISO 717-1: Acoustics - Rating of sound insulation in buildings and of building elements - Part 1: Airborne sound insulation. Genebra, 2013. 